\title{
FILOLOGIA $\in$ LINGÜÍSTICA: ENLACE, DIVÓRCIO, RECONCILIAÇÃO
}

Pierre Swiggers"

RESUMO: O artigo trata das relações entre a Filologia e a Linguística ao longo da história dos estudos da linguagem e procura definir os respectivos objetos e campos de trabalho. Apresenta a questão da ambiguiidade da filologia, apontando o seu domínio amplo (estudos linguísticos, literários e edição de textos) e restrito (ciência do estabelecimento de uma edição crítica). A seguir, trata das relações entre Filologia e Linguiística como sendo de complementaridade e não de antagonismo, uma vez que desenvolvem relações intrínsecas. Finalmente, após considerar pontos fundamentais ao trabalho filológico, mostra a relação de englobamento entre Filologia e Linguiística como resultado de um trabalho conjunto de ambas.

Palavras-chave: filologia, linguística, linguística histórica e comparativa, complementaridade, englobamento.

\section{INTRODUÇÃO}

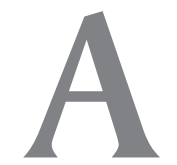

s relações entre filologia e linguiística são hoje difíceis de avaliar, considerando que todo linguiista e todo filólogo são colocados face ao problema de definir sua atitude diante dessas relações. Uma posição bastante 'liberal' consiste em tomar o termo 'filologia' num sentido bastante amplo, como acumulação extensiva de três domínios (ou níveis) de estudo: linguíística, literatura e edição de textos (ou 'filologia no sentido estrito'). Incluída em si mesma, a filologia desliza, portanto, do estudo de línguas (e de textos) à ciência (ou a arte, cf. Bédier: 'a arte de editar textos') de estabelecer uma edição crítica dos textos. A filologia no sentido restrito não é pois senão um resumo da filologia total - visto que ela implica um comentário linguiístico e literário -, mas a sua especificidade parece

\footnotetext{
Diretor de Pesquisa - Fonds National de la Recherche Scientifique - Bélgica.
} 
SWIGGERS, Pierre. Filologia e Lingüística: enlace, divórcio, reconciliação.

residir na aplicação feita a um tipo particular de objetos: textos que necessitam de uma apresentação 'crítica'.

Se tal cristalização dos estudos linguísticos e literários na concepção da filologia 'no sentito estrito' já coloca o problema da ambiguiidade do termo 'filologia' e o da conveniência que há em distinguir uma filologia no sentido amplo e uma filologia no sentido restrito, mais ainda se manifesta a complexidade, de modo pragmático, quando se examina a política das revistas: a edição dos textos não está necessariamente ligada a uma 'bandeira filológica' (cf. a Romania, Medioevo romanzo) e, por outro lado, parece que certas revistas que trazem o termo 'filologia' (ou port./ital. filologia, esp. filología, gal. filoloxía, ingl. philology) no seu título não são muito favoráveis à literatura.

\section{ABORDAGEM HISTÓRICA}

O termo 'filologia' evoluiu' da significação de 'conhecimento do homem letrado' à de 'estudo científico das línguas e das literaturas'. É essa última significação, com aplicação ao domínio românico, que se encontra em F. Neumann em 1886 (Die romanische Philologie. Ein Grundriss, em 1886, p. 5) e que se perpetuou em manuais como o de C. Tagliavini: "La filologia romanza ha per oggetto lo studio, prevalentemente storico e comparato, delle lingue e letterature romanze e neolatine" [trad. "A filologia românica tem por objeto o estudo, principalmente histórico e comparado, das línguas e das literaturas românicas e neolatinas"] (Tagliavini, 1972, p. 1). O acréscimo do adjetivo comparato nessa definição tinha sido condenado por J. Engels (1953, p. 20$)^{2}$; erradamente, cremos, pois o adjetivo exprime bem o ideal da filologia do século XIX e da primeira metade do

1 Sobre o termo e a sua evolução, ver Vasconcelos (1946), Bernardini Righi (1947), Nuchelmans (1950) e Swiggers (1989).

2 "Creio que a adjunção desse adjetivo comparato, comparado é pouco feliz. O estudo das línguas românicas será frequientemente comparativo, mas não sempre, nem talvez de for- 
Filologia e Lingüística Portuguesa, n. 2, p. 5-18, 1998.

século XX: a filologia é a disciplina que, partindo dos textos - quer se trate dos Vedas, da epopéia dos Mahrabhrrata, da Bíblia gótica, da poesia dos trovadores provençais -, estuda estados de língua, compara-os a outros estados da mesma língua ou a cortes sincrônicos de outras línguas, a fim de reconstituir a história de uma língua ou de uma família de línguas. Sabe-se a que descobertas e que problemas essas pesquisas conduziram: à natureza (e à regularidade) da mudança linguiística, à noção de parentesco linguiístico, à língua como um jogo de forças (economia, menor esforço, analogia...), às metáforas biológicas aplicadas às línguas (nascimento, desenvolvimento, degenerescência, morte), e à equação muito fácil entre 'língua', 'raça' e 'cultura'. Essa filologia do século XIX (chamada 'comparative philology' em inglês, 'ciência comparativa das línguas'3 ou 'filologia comparativa') era profundamente linguiística ${ }^{4}$ - no mundo anglo-saxão o termo philology foi, durante muito tempo, um testemunho direto desse estado de coisas ${ }^{5}$ - e, se ela ultrapassava o quadro linguiístico, não era para comprazer-se nos estudos literários ou estilísticos, mas antes para abrir-se à história dos povos e das culturas: perspectiva traçada por A. F. Wolf em sua Darstellung der Alterthumswissenschaft e prontamente aplicada às filologias modernas ${ }^{6}$. $\mathrm{O}$ elo entre filologia

ma absoluta: pensemos no problema sincronismo-diacronismo. A seguir, conforme já o fizemos observar com razão, será também necessário compará-las, eventualmente, com línguas não-românicas, mas contemporâneas".

3 Ver a edição e o comentário de um texto programático (datado de 1836) de P.S. Du Ponceau, em Swiggers (1992).

4 A respeito das bases linguísticas e antropológicas dessa filologia comparada, ver Swiggers (1993).

5 Ver a esse respeito Bolling (1929); sobre o conceito de general philology, ver Malkiel (19601961) e Malkiel (1966).

6 Ver a seguinte passagem no Grundriss de Gröber (1888: 152-153) que, em sua "Articulação da filologia românica" ("Gliederung der romanischen Philologie") inclui a etnologia e a história dos povos: "A parte historiográfica, que reúne os fatos mais importantes para a filologia românica, das ciências históricas vizinhas e que indica as fontes e os instrumentos mais importantes, disponíveis por ela e como introdução a essa disciplina, começa naturalmente com uma seção ETNOLÓGICA, que informa a respeito dos povos que habita- 
SWIGGERS, Pierre. Filologia e Lingüística: enlace, divórcio, reconciliação.

e história cultural foi sempre posto em evidência na tradição antropolinguíística americana (cf. Hymes, 1976).

Se hoje não se pratica mais essa filologia compósita, isto não se deve (tanto) ao reconhecimento, no interior da filologia, de metodologias heterogêneas ou, de qualquer forma, divergentes, mas a um dado pragmático, o da 'divisão do trabalho': por um lado, o desenvolvimento dos estudos linguiísticos (basta pensar na especialização crescente em fonética, morfossintaxe e semântica e no desenvolvimento de 'paradisciplinas' como a sociolinguiística, a psicolinguíística, a etnolinguiística e a linguíística aplicada) e, por outro, a evolução paralela dos estudos literários (poética; tematologia; antropologia e semiótica literárias; literaturas comparadas; hermenêutica literária) tornam impossível, para pesquisadores individuais, um domínio unificado. Essa clivagem aparece em certos manuais recentes ${ }^{7}$, como o de Gauger Oesterreicher - Windisch (1981), em que se lê que a linguiística românica (romanische Sprachwissenschaft) e os estudos literários românicos (romanische Literaturwissenschaft) são duas disciplinas nitidamente separadas $^{8}$. Evidentemente, poder-se-á retorquir que outros manuais

ram os países românicos, de acordo com o seu aspecto físico e as suas particularidades espirituais. Por outro lado, uma segunda seção HISTÓRICA informa acerca das expressões e realizações espirituais dos povos românicos, com exceção dos fatos linguíísticos e literários, quer dizer, portanto: A) sobre a história política românica e sobre as vicissitudes das nações e povos românicos; B) sobre o estado cultural desses povos, suas formas de vida, instituições civis, costumes, hábitos, atividades, contactos e a isto pertence o que a etnologia fornece como conhecimento acerca das crenças, superstições e usos do povo etc. ( história cultural no sentido restrito); sobre a atividade artística dos povos românicos ( história da arte) [...]; D) sobre as ciências ( história da ciência)" [ Trad. a partir do francês].

7 Ver também Vidos (1956), Iordan (1962) e Bal (1966) no domínio dos estudos românicos.

8 “A disciplina 'Filologia Românica' há muito não constitui mais uma unidade. Ela se desintegra - a expressão não é inadequada - em duas disciplinas separadas: a linguíística românica, de um lado, e os estudos literários românicos, de outro. A diversidade dessas disciplinas reside, antes de tudo, na diversidade do objeto: o objeto da linguística românica é constituído pelas línguas românicas, provenientes do latim; o objeto dos estudos literários românicos é constituído pelas literaturas escritas nessas línguas" [Trad. a partir do francês]. Orig. "Das Fach 'Romanische Philologie' bildet seit langem keine Einheit mehr. Es zerfält der Ausdruck ist nicht unangemessen - in zwei getrennte Disziplinen: die Romanische 
Filologia e Lingüística Portuguesa, n. 2, p. 5-18, 1998.

- que se inscrevem na corrente 'idealista' (Vossler, Menéndez Pidal, Spitzer, etc.) - apresentam uma tentativa de unificação; mas a síntese é sempre imperfeita e não atribui o mesmo peso ao aspecto literário e ao aspecto linguiístico.

A ambiguiidade da filologia, com tudo o que ela assume de promissor e de ultrapassado, obriga-nos a retomar, como temática fundamental, o problema da relação entre a linguiística e a filologia.

\title{
3. UMA EVOCAÇÃO HISTÓRICA $\in$ UMA LIÇÃO DE MÉTODO
}

No século XIX, a filologia e a linguiística ('Glottik', 'Sprachwissenschaft' em alemão; 'glottologia' em italiano) ${ }^{9}$ mantinham relações antagonistas. Em 1844, nos Blätter für literarische Unterhaltung, um jovem romanista alemão, August Fuchs, reagiu contra essa situação e colocou em relevo a complementaridade entre filologia e linguíística:

\begin{abstract}
"A idéia pré-concebida de que os pesquisadores, no que toca à linguagem, se dividem em filólogos, ou seja, pesquisadores no domínio do grego e do latim, e em lingüistas, isto é, pesquisadores no domínio de outras línguas, deve ser abolida, visto que lembra bastante a antiga unilateralidade e o espírito de dominação dos primeiros, pois julgavam que fora o latim e o grego não havia nenhuma outra língua culta e olhavam com pena e desdém a preocupação com outras línguas, como se se tratasse de uma aberração. Os pesquisadores que se julgavam privilegiados foram punidos por sua arrogância, uma vez que tiveram que reconhecer que, graças justamente aos lingüistas menosprezados, uma mudança salutar operou-se na filologia; os linguiistas realizaram mais, em poucos anos, pela linguiística geral, pelo sânscrito, pelas línguas germânicas e ro-
\end{abstract}

Sprachwissenschaft einerseits, die romanische Literaturwissenschaft andererseits [...] Ihre Verschiedenheit liegt vor allem in der Verschiedenheit des Gegenstand der romanischen Sprachwissenschaft sind die romanischen, also die vom Lateinischen herkommenden Sprachen; Gegestand der romanischen Literaturwissenschaft sind die in diesen Sprachen geschriebenen Literaturen" (Gauger - Oesterreicher - Windisch, 1981, p. 3).

9 Com exceção do italiano, as línguas românicas adotaram em geral a designação da disciplina, baseada no termo latino (termo de classificação, sob a forma de um neutro plural) linguistica. A respeito dos primeiros empregos do termo, ver Swiggers (1966). 
SWIGGERS, Pierre. Filologia e Lingüística: enlace, divórcio, reconciliação.

mânicas, que os filólogos em alguns séculos pelo estudo aprofundado da língua grega e latina - estudo que somente progrediu significativamente, de modo direto e indireto, por intermédio da linguística moderna. É necessário, portanto, acabar com essa separação odiosa e falsa da filologia e da linguística, dos filólogos e dos linguiistas. Estes não podem dispensar aqueles e vice-versa e ainda menos pela razão de que constataram que aqueles [ = os lingüistas] não perdem em nada para eles em questão de cientificidade e que os superam mesmo em polivalência. Não poderia tratar-se aqui de "artesãos", de que se tem um número suficiente nos dois domínios. O nome de "pesquisador em assuntos de linguagem' não convém perfeitamente tanto a um como a outro: nome pelo qual fica abolida qualquer separação e que indica, ao mesmo tempo, que nenhuma língua é excluída da abordagem científica e que é, antes, a língua em todas as suas variadas manifestações que constitui objeto de exame? Se se objetar que o nome 'filologia' inclui simultaneamente a preocupação com a antigüidade, notar-se-á em primeiro lugar que isto não se deve senão a uma significação que se introduziu no nome; em segundo lugar, que é somente a antiguiidade grega e latina, portanto, uma pequena parte da antiguiidade dentro de sua totalidade, que é estudada pelos filólogos; e em terceiro lugar que, aquele que estuda as línguas da Índia e as línguas semíticas etc. não pode igualmente dispensar o conhecimento das antiguiidades, isto é, da vida privada, pública, artística e moral dos povos em questão; os filólogos não têm, portanto, a esse respeito, nenhuma vantagem sobre os linguiistas, os quais têm um campo igualmente vasto, ou mesmo mais vasto a cultivar, pois o verdadeiro lingüista deve primeiramente ser filólogo, antes de poder tornar-se linguiista"10 [ Trad. a partir do francês].

10 "Das Vorurtheil, dass die Sprachforscher in Philologen, d.i. Forscher in griechischer und lateinischer Sprache, und Linguisten, d.i. Forscher in andern Sprachen, zerfallen, muss niedergerissen werden, denn es erinnert zu sehr an die alte Einseitigkeit und Herrschsucht der Erstern, da sie noch meinten, dass es ausser Griechisch und Lateinisch keine gebldete Sprache gäbe, und da sie auf die Beschäftigung mit andern Sprachen wie auf eine Verirrung mitleidig oder verächtlich herabschauten. Die sich bevorrechtet dünkenden Sprachfiorcher sind für ihre Anmassung gestraft worden, denn sie haben anerkennen müssen, dass gerade durch die geringgeschässten 'Linguisten' haben in wenigenjahren mehr für die allgemeine Sprachkunde, für das Sanskrit, für die germanischen und romanischen Sprachen u.s.w. gewonnwn, als die 'Philologen' in einigen Jahrhunderten für die gründliche Erforschung der griechischen und lateinischen Sprache, die erst durch die neuere Sprachwissenschaft mittelbar und unmittelbar bedeutend weiter gefördert worden ist. Also weg mit dieser gehässigen und unwahren Scheidung awischen Philologie und Linguistik, zwischen philologen und Linguisten! Diese können jener, jene aber auch dieser nicht entbehren, um so weniger, seitdem sie gesehen haben, dass diese ihnen an echter Wissenschaftlichkeit nichts nachgeben, an Vielseitigkeit aber sie übertreffen. Von den Handwerkwn, deren es freilich auf beiden Gebieten genug gibt, kann hier natürlich keine Rede sein. Ist nicht für die Einem wie für die Andern der Name Sprachforscher, durch den jene Spaltung aufgehoben und zugleich angedeutet wird, dass keine Sprache von wissenschaftlicher Betrachtung ausgeschlossen werden, dass vielmehr die Sprache in allen ihren verschiedenen Áusserung untersucht werden soll, der passendste? Wenn man einwendet, der Name Philologie 
Filologia e Lingüística Portuguesa, n. 2, p. 5-18, 1998.

Em 1862, Georg Curtius defenderá também uma aproximação entre a 'Filologia' e a 'Sprachwissenschaft'11.

Do ponto de vista metodológico, de fato será difícil justificar uma clivagem entre a atividade filológica e a atividade linguiística. Há, além disso, domínios de pesquisa em que a conjunção dos dois tipos de atividade é indispensável ${ }^{12}$; pode-se também pensar na obra de alguns brilhantes linguiistas-filólogos, tais como Jakob Wackernagel, Émile Benveniste ou Piero Meriggi.

\section{O LUGAR ESPECÍFICO DA FILOLOGIA}

Se a reciprocidade dos conhecimentos de ordem linguiística e filológica (segundo as distinções tradicionais) é inegável, poder-se-ia entretanto reservar um lugar particular à filologia e justificá-lo por duas propriedades essenciais; (1) o trabalho sobre textos escritos; (2) um esforço descritivo voltado para esses textos.

A conjunção dessas duas propriedades é indispensável para que se possa falar de 'filologia'. De fato, os textos escritos - quer funcionem como fontes diretas ou indiretas (pelo desvio de sínteses inter-

schliesse zugleich die Beschäftigung mit der Alterthumskunde in sich, so ist dies erstens nue eine in das Wort hineingetragene Bedeutung, zweitens sind es wiederum nur die griechischen und römischen Alterhümer, also nue ein Kleiner Theil der ganzen Alterhumskunde, die den Philologen beschäftigen, und drittens kann der indische, der semitische u.s.w. Sprachforscher ebenso wenig der Kunde von den Alterthümern, d.h. vom häuslichen, öffentlichen, künstlerischen und sittlichen Leben der betreffenden Völker entbehren; die Philologen haben also hieren gar nichts von der Linguisten voraus, die uiberhaupt ein eben so weites, ja ein weiteres Feld zu benauen haben als jene, denn der wahre Linguist muss erst Philologe sein, ehe er Linguist werdwen kann (Fuchs, 1844, p. 1247).

11 Cf. Curtius (1862) = Christmann (ed.1977, p. 67-84). Para outros defensores (de Hoefer e de Brugmann) ver Koerner (1982, p. 410). Sobre Fuchs, ver Storost (1984).

12 Lembremos aqui da defesa de R. Antilla $(1972 ; 1973)$ em favor de uma harmonização da filologia e da lingüística (histórica). 
SWIGGERS, Pierre. Filologia e Lingüística: enlace, divórcio, reconciliação.

mediárias) - estão também na base de trabalhos linguiísticos: gramáticas históricas, dicionários etimológicos, ou atlas linguiísticos. A filologia, porém, exige o retorno ao estabelecimento de um texto, com vistas a uma edição crítica e/ou a um comentário linguiístico.

A propósito dos textos, objetos da filologia, convém colocar algumas questões, às quais os filólogos nem sempre responderam:

(1) Tratar-se-á de textos escritos? No contexto da filologia clássica, românica ou germânica, essa questão poderia parecer retórica. São os filólogos, todavia, capazes de fornecer uma definição do texto, mesmo do texto escrito, e não deveriam voltar-se aqui para os lingüiistas? ${ }^{13}$. Constata-se, além disso, que os antropolingüistas americanos constituíram, desde Boas, uma filologia de textos orais: rica tradição, ilustrada, entre outros, pelos trabalhos de Boas, Sapir, Bloomfield, Swadesh, Hoijer, Kroeber, Voegelin, e Dell Hymes ${ }^{14}$. Pode-se falar, a esse respeito, de uma 'filologia sincrônica', como o faz Anttila (1973, p. $184-5)^{15}$.

(2) Devem esses textos apresentar um caráter literário? Essa questão me parece importante, dado que alguns de nossos instrumentos de trabalho (dicionários ou gramáticas históricas, ou as descrições de um estado de língua acabado) são centrados sobre a forma linguiística que os textos literários assumem. Qual é, contudo, o critério de 'literariedade’? (Nem o formalismo russo, nem o estruturalismo de Praga puderam definir a 'literariedade') e - questão mais importante ainda - como se pode definir essa literariedade em relação à época medieval, por exemplo? Não se poderia negar que textos que nunca foram objeto de uma recepção estética representam um grande interesse para o filólogo: que se pense nas cartas, nos testamentos, nos glossários, ou nos tratados científicos (de que se pode tirar um grande proveito linguístico).

13 Penso aqui na 'discourse analysis', desenvolvida por Zellig Harris e na lingî́stica do texto (cf. Dressler 1972, ed. 1978; Dressler - Schmidt 1973; de Beaugrande - Dressler 1981).

14 Ver a esse respeito nossas observações em Swiggers (1982).

15 Ver também os seguintes textos metodológicos: Goddard (1973) e Hymes (1965a,1965b,1983). 
(3) É necessário também que se volte para o alvo das edições críticas, uma vez que a filologia é frequientemente concebida como a disciplina da palavra que se tornou incompreensível ${ }^{16}$. Parece-me que as edições críticas cumprem uma destinação ambígua. Por um lado, trata-se de restituir o texto original ou, pelo menos, de apresentar o texto autêntico de uma cópia particular; por outro, a edição crítica volta-se para o autor moderno, por sua pontuação e pelo emprego de sinais diacríticos. Constituem as veneráveis regras da edição crítica um compromisso entre a aspiração à fidelidade do historiador e a busca da legibilidade do editor de textos? Como, porém, justificar esse compromisso em relação à percepção e à recepção medievais desses textos (e a organização de seu conjunto) e em relação à coerência metodológica que a abordagem linguiística exige?

\section{RELAÇÕES $\in$ RECONCILIAÇÃO}

A filologia e a linguiística têm relações intrínsecas. Conforme observava Antoine Meillet em 1925, uma pode servir de entrada à

16 Cf. Gröber (1888, p.146): “E se uma língua ou a linguagem fosse imutável, não haveria absolutamente possibilidade de filologia. É aqui que se reconhece, sem ambiguiidade, o campo da atividade específica do filólogo: o discurso e a língua não compreendidos, ou que se tornaram incompreensíveis. Somente nesse caso, o investigador do passado de um campo de realizações espirituais tem necessidade de ajuda do filólogo. Aliás, não é senão junto a ele que encontrará ajuda: somente ele [o filólogo] possui a chave que permite abrir a significação do escrito mudo, somente ele faz com que os tempos passados nos falem e que as línguas desconhecidas nos sejam compreensíveis; a filologia é, portanto, a ciência do discurso desconhecido" [Trad. a partir do francês]. Orig. Alemão: "Und wäre gar eine Sprache oder die Sprache unveränderlich, so würde von Philologie überhaupt nicht geredt werded können. Hieran aber gibt sich als das Gebiet der eigensten Thätigkeit des Philologuen unzweideutig zu erkennen: die unverstandene oder unverständlich gewoedene Rede und Sprache. Erst wo diese vorhanden, bedart der Erforscher der Vergangenheit eines Gebietes geistiger Leistungen der Hilfe des Philologen. Aber auch nur bei ihm Kann er sie finden, nur er besitzt die Schüssel zur Eröffnung des Sinnes des stummen Schriftzeichens, nur er lässt vergangene Zeiten zu uns reden und fremde Zungen uns verstehen; die Wissenschaft also von frender Rede ist Philologie". 
SWIGGERS, Pierre. Filologia e Lingüística: enlace, divórcio, reconciliação.

outra: "Para determinar os estados de língua do passado, o lingüista deve servir-se da mais exata filologia, da mais precisa: e cada progresso na precisão filológica permite um novo progresso para o lingüista. O contacto cada vez mais estreito que, felizmente, se estabeleceu entre filólogos e comparatistas, é necessário para que o linguiista possa utilizar todos os fatos, fatos seguros, e fatos observados com a máxima precisão. Sozinha, contudo, a filologia não traz nem mesmo um começo de história linguiística" (Meillet, 1925, p.11). Ao lado dessa relação 'linear', há também uma relação 'interna', de controle metodológico e empírico, como o observou Robert Stockwell (1982):

\begin{abstract}
"Mais do que a distinção entre 'Filologia'e 'Lingüística', a distinção que eu gostaria de destacar é aquela entre teoria da construção, por um lado, e a tarefa de acompanhamento de confirmação/ desconfirmação. A filologia proporciona apenas os melhores dados que nós temos para confirmação e desconfirmação de certas espécies de teorias que têm sido construídas independentemente daqueles dados. Tradicionalmente, os filólogos não têm se preocupado muito com a teoria da construção e os lingüistas teóricos que constroem teorias têm, freqüentemente, uma base empírica bastante fraca. Não vejo como os dois podem deixar de se apoiar mutuamente, cada um com muito que aprender do outro. O desprezo de alguns filólogos pela teoria da construção é tão mal orientado quanto lamentáveis as inadequações empíricas de alguns lingüistas teóricos" ${ }^{17}$.
\end{abstract}

Pode-se pensar aqui no perigo das 'gafes etimológicas' e no das más lições (cf. Baldinger, 1973,1974). Há, finalmente, um relação de englobamento, não só no nível dos conhecimentos, mas também no nível dos corpora respectivos. A filologia engloba a linguística, na

17 Orig. "Rather than the distinction between 'Philology'and 'Linguistics', the distinction I would like to highlight is that between theory construction, on the one hand, and the follow-up task of confirmation/disconfirmation of certain kinds of theories that have been constructed independently of that data. Traditionally philologists have not been much concerned with theory construction, and the theoretical linguists who construct theories often have a rather weak empirical base. I do not see how the two can fail to be mutually supportive, each with much to learn from the other. The scorn of some philologists for theory construction is as misdirected as the empirical inadequacies of some theoretical linguists are regrettable." 
Filologia e Lingüística Portuguesa, n. 2, p. 5-18, 1998.

medida em que é necessário fazer também uma filologia da lingüística: a filologia toma, então, como objeto o discurso dos linguiistas e, de modo bem particular, a sua terminologia descritiva. Como exemplos dessa filologia enquanto "metalinguística", eu gostaria de assinalar no nível macroscópico - os dicionários de termos linguiísticos, estabelecidos a partir de um corpus de escritos linguiísticos (cf. Hamp 1966; Engler 1968; Vachek 1970), e - no nível microscópico - dois artigos que dediquei ao registro 'metalinguiístico' do Donait françois (Swiggers 1985, 1986). Inversamente, existe também uma metafilologia, no sentido de que o linguiista examina e julga o corpus filológico e a prática que este reflete.

Que essa relação de englobamento - filologia e linguiística como caixas chinesas - venha à luz nos grandes empreendimentos de lexicografia histórica, não deve nos espantar: é o trabalho filológico que nos ajuda a reconstruir a perspectiva temporal na história das línguas. A descoberta da cronologia interna é o resultado de um trabalho combinado de filologia e de linguiística: é este trabalho que é o fundamento da verdadeira linguiística histórica, tal como Sapir a elaborou em sua notável monografia de 1916, Time Perspective in Aboriginal American Culture.

Tradução de Lineide do Lago Salvador Mosca

\section{BIBLIOGRAFIA}

ANTTILA, R. (1972) An introduction to historical and comparative linguistics. New York - London, Macmillan.

(1973) Linguistik und Philologie. In BARTSCH, R. \& VENNEMANN, Th. (eds), Linguistik und Nachbarwissenschaften. Kronberg, Scriptor Verlag, p. 177-91.

BAL, W. (1966) Introduction aux études de linguistique romane, avec considération spéciale de la linguistique française. Paris, Didier.

BALDINGER, K. (1973) Ancien français garger. Les deux vies d'un mot fantôme. Études de langue et de littérature du moyen âge offertes à Félix Lecoy, 1-6. Paris, Champion. 
SWIGGERS, Pierre. Filologia e Lingüística: enlace, divórcio, reconciliação.

(1974) Les 'gaffes' des lexicographes. Studia hispanica in honorem R. Lapesa, vol. II, Madrid, Gredos, p. 81-7.

BERNARDINI, A. \& RIGHI, G. (1947) Il concetto di filologia e di cultura classica dal Rinascimento ad oggi. Bari, Laterza.

BOLLING, G.M. (1929) Linguistics and Philology. Language, 5, p. 27-32.

CHRISTMANN, H.H. (ed.) (1977) Sprachwissenschaft des 19. Jahrhunderts. Darmstadt, Wissenschaftliche Buchgesellschaft.

CURTIUS, G. (1862) Philologie und Sprachwissenschaft. [Retomado em: CURTIUS, G. Kleine Schriften, hrsg. von E. WINDISCH, I. Theil, Leipzig, Hirzel], p. 132-50.

DE BEAUGRANDE, R. \& DRESSLER, W. (1981) Introduction to text linguistics. London, Longman.

DRESSLER, W. (1972) Einführung in die Textlinguistik. Tübingen, Niemeyer. (ed.) (1978) Textlinguistik. Darmstadt, Wissenschaftliche Buchgesellschaft. \& SCHMIDT, S. (1973) Textlinguistik. München, Fink.

ENGELS, J. (1953) Philologie romane - Linguistique - Études littéraires. Neophilologus, 37, p.14-24.

ENGLER, R. (1968) Lexique de la terminologie saussurienne. Utrecht - Anvers, Spectrum.

FUCHS, A. (1844) Die Versammlung deutscher Sprachforscher und Schulmänner in Dresden am 1-4. Oct. 1844. Blätter für literarische Unterhaltung 312. 1245-47; 313. 1249-51.

GAUGER, H.-M.; OESTERREICHER, W. \& WINDISCH, R. (1981). Einführung in die romanische Sprachwissenschaft. Darmstadt, Wissenschaftliche Buchgesellschaft.

GODDARD, I. (1973) Philological approaches to the study of North American indian languages: documents and documentation. In SEBEOK, Th. A. (ed.), Current trends in linguistics, vol. X. The Hague, Mouton, p. 727-47.

GRÖBER, G. (1888) Grundriss der romanischen Philologie. I. Band: Geschichte und Aufgabe der romanischen Philologie - Quellen der romanischen Philologie und deren Behandlung Romanische Sprachwissenschaft. Strassburg, K. Trübner.

HAMP, E.P. (1966) A glossary of American technical linguistic usage 1925-1950. Utrecht Antwerp, Spectrum.

HYMES, D. (1965a) Some North pacific coast poems: a problem in anthropological philology. American Anthropologist, 67, p. 316-41. p. $325-40$.

(1965b) Methods and tasks of anthropological philology. Romance Philology, 19,

(1976) The americanist tradition. In CHAFE, W. (ed.), American indian languages and American linguistics. Lisse, Peter de Ridder Press, p. 11-28.

(1983) In vain I tried to tell you... Philadelphia, University of Pennsylvania Press.

IORDAN, I. (1962) Lingvistica romanica. Evoluie, curente, metode. Bucure, Ed. Academiei R.P.R.

KOERNER, K. (1982) On the historical roots of the philology/linguistics controversy. In AHLQVIST, A. (ed.), Papers from the 5th international conference on historical linguistics, Amsterdam, Benjamins, p. 404-13. 
Filologia e Lingüística Portuguesa, n. 2, p. 5-18, 1998.

MALKIEL, Y. (1960-61) Three definitions of romance linguistics. Romance Philology, 15, p.1-7. (1966) "Is there room for 'general philology'?". Pacific Coast Philology, 1, p. 3-11.

MEILLET, A. (1925) La méthode comparative en linguistique historique. Paris, Champion.

NUCHELMANS, G.R.F. (1950) Studien über filovlogo, filologiva und filologei'n. Zwolle, Tjeen Willink.

SAPIR, E. (1916) Time perspective in aboriginal American culture. (Canada, Department of Mines, Anthropological Series n 13, Memoir 90). Ottawa, National Museum.

STOCKWELL, R.P. (1982) [Intervenção na discussão a respeito das relações entre a filologia e a linguiística histórica]. In AHLQVIST, A. (ed.), Papers from the 5th International Conference on Historical Linguistics. Amsterdam, Benjamins, p. 451-2.

STOROST, J. (1984) August Fuchs, Philolog. Beiträge zur Romanischen Philologie, 23, p. 95-108.

SWIGGERS, P. (1982) Linguistique amérindienne et anthroposémantique. Cahiers de l'Institut de Linguistique de Louvain, 8, p. 75-82.

(1985) Un emploi grammatical du mot epiloge en moyen français. Zeitschrift für romanische Philologie, 101, p. 413-16. p. $129-32$.

(1986) Miel a enbeure: un 'nom complectif'. Revue de Linguistique Romane, 50, p. 89-106.

(1989) Filologie. Wetenschap Nu en Morgen. Leuven, Leuven University Press,

(1992) Peter Stephen Du Ponceau et la philologie définie comme science comparative des langues. Cahiers de l'Institut de Linguistique de Louvain, 18/3-4, p. 5-16.

(1993) Létude comparative des langues vers 1830. Humboldt, Du Ponceau, Klaproth et le baron de Mérian. In DROIXHE, D. \& GRELL, Ch. (eds.), La linguistique entre mythe et histoire. Münster, Nodus, p. 275-95.

(1996) A note on the history of the term linguistics. With a letter from Peter Stephen Du Ponceau to Joseph von Hammer-Purgstall. Beiträge zur Geschichte der Sprachwissenschaft, 6, p. 1-17.

TAGLIAVINI, C. (1972). Le origini delle lingue neolatine. Introduzione alla filologia romanza. Bologna, Pàtron. [1949; 1952; 1953; 1959; 1969]

VACHEK, J. (1970) Dictionnaire de linguistique de l'École de Prague. 3. ed. Com a colaboração de J. Dubsk. Utrecht - Anvers, Spectrum.

VASCONCELOS, C. Michaëlis de (1946) Lições de filologia portuguesa. Lisboa, Dinalivro.

VIDOS, B.E. (1956) Handboek tot de Romaanse taalkunde. 's-Hertogenbosch, Malmberg.

[Trad.em espanhol, Manual de lingüística románica. 2. ed. Madrid, Aguilar,1968]

ABSTRACT: The article deals with the relationships between Philology and Linguistics along the history of the studies of the language and seeks to define the respective objects and fields 
SWIGGERS, Pierre. Filologia e Lingüística: enlace, divórcio, reconciliação.

of analysis. It presents the question of the philology's ambiguity, pointing out its broad scope (linguistic and literary studies, as well as the editing of texts) and its restrict scope (the science of the establishment of a critical edition). Next, it tackles the relationships between Philology and Linguistics, which are complementary and not antagonic since they yield intrinsic relationships. Finally, after considering fundamental issues to philologic analysis, the article presents the relationships of involvement between Philology and Linguistics as a result of a joint work of both.

Keywords: philology, linguistics, historical-comparative linguistics, "complementarity", involvement. 